\title{
Convergence of technologies and journalists: Translation of journalistic practices through ANT perspective
}

\author{
Anoop Kumar \& M. Shuaib Mohamed Haneef \\ Pondicherry University \\ E-mail: anoop.bhumasscommegmail.com/shuji22@gmail.com
}

\begin{abstract}
The field of journalism has always been inflected by technological disruptions that take place continually. Disruption ushered in by the digitalisation and convergence of media has changed the ways journalists perform their routine journalistic tasks. Non-human actants like mobile phones, smart phones, messaging apps, and social media among others have influenced journalistic practices in the realm of converged media. This research paper attempts to explore how smart phones, social media and other convergent media and related practices alter or translate the journalistic network of news production. To understand the phenomena, the researchers conducted in-depth interview with twelve journalists from the Hindustan Times and Hindustan Dainik, Lucknow and Dainik Jagran, Allahabad, Uttar Pradesh. The audio recordings of interviews were tran-

scribed and coded as per the three stages of thematic analysis using qualitative data analysis software NVivo. Emerging literature on convergence journalism and actor-network theory has been invoked for analysis and discussion. The analysis shows that journalists from all three newspapers are adept at dealing with converged technologies and concomitant practices. News technologies like WhatsApp, Facebook, Twitter, the content management software or central server (NewsWrap) and page-making software namely QuarkXPress and Adobe InDesign have become prominent non-human actors performing the role of mediators. The attendant practices of these news technologies indicate substantial translation of the journalistic network in terms of how journalists do their work and how the resources of the organisation and the knowledge produced are coordinated.
\end{abstract}

Keywords: media convergence; journalists; ANT; translation; black box.

Data de submissão: 2016-05-10. Data de aprovação: 2016-05-25. 


\section{Introduction}

THE MIT political scientist Ithiel de Sola Pool has been hailed as the Prophet of convergence by Jenkins (2006). It was Ithiel de Sola Pool who for the first outlined the concept of convergence. Multimedia and interactivity have been identified as salient capabilities of convergent media (Boczkowski, 2004). Media convergence has been defined as:

...the flow of content across multiple media platforms, the cooperation between multiple media industries, and the migratory behaviour of media audiences... (Jenkins, 2006, p.2)

There have been several areas of convergence such as "device, network and content" (Flynn, as cited by Appelgren, 2004) and "social or organic convergence and technological convergence" among others proposed by Jenkins (2001). While social convergence deals with the multi-tasking behaviour of users, technological convergence is concerned with the flow of digital information across platforms. While Negroponte (1989) envisaged convergence as merging of the publishing, broadcasting and computer industry, Dubberly (2011) proposed convergence 2.0 model which is comprised of internet-based services, social network and the physical world. Pavlik (2000) sees journalism as technologically enabled exercise. Technology has affected how journalists do their job and the contours of relationship among journalists, readers and sources (Pavlik, 2000). There has been sea-change when it comes to the relationship of journalists with their sources and readers ushered in by convergence practices (Pavlik, 2004). The phenomenon of media convergence has brought disruption from the beginning and is continuously altering and/or shaping the way journalists do their job.

Convergence is more than merely technological change rather it has different cultural dimensions (Jenkins, 2004). The alteration caused by media convergence affects the "relationship between existing technologies, industries, markets, genres and audiences" (Jenkins, 2004). Robinson (2011) sees convergence as 'crises' and demonstrates in his study that power hierarchies has changed with the introduction of digital technologies and in such an environment, news workers having technical skills enjoy a relatively privileged position compared to those having cultural mind-sets of print domain. Cottle and Ashton (1999) challenge the technological myopia and determinism 
and conceive of technology as socially and culturally shaped and embedded in corporate and professional culture.

By combining the diffusion of innovation theory and actor-network theory, Micó, et al. (2013) demonstrated in their seminal work that the outcomes of convergence process were unpredictable and largely shaped by the dynamics of groups involved in the process. Unlike the diffusion of innovation theory (Rogers, 1995) which predicts the trajectories of innovation process well in advance, the actor-network theory (Latour and Woolgar, 1979) recognises the processual dynamics of any innovation and points out at the unpredictability of the trajectories of any innovation and its final outcome.

This research paper attempts to explore how 'news technologies' and related practices alter or translate the 'journalistic network' of news production. Further, this research paper explores how certain actors in the newsroom become the indispensable part of the news production process and how some of them become the obligatory point of passage for most of the news-related activities. Again, the resistance put forward by other actors against any change or translation process has also been explored. The researchers have used actornetwork theory as the theoretical framework to understand the research subject.

News technologies encompass a range of applications (software and hardware) which include the social networking sites, blogging and micro-blogging sites, messaging apps, computer, internet, mobile phone, smart phone, pagemaking software and content management software. In addition, journalistic network is defined as assemblage of all journalists, organisational set up, technologies, network, statements, guidelines and the knowledge produced. Journalistic network shapes how and what kind of knowledge/news would be produced.

Building on the above proposition, this study is guided by the following research question (RQ).

RQ1. How 'news technologies' and related practices alter or translate the 'journalistic network' of news production?

\section{Theoretical framework}

Actor-network theory (ANT) was developed through the works of Bruno Latour, French philosopher and Steve Woolgar, a British sociologist. Later the 
ANT, important theory of the Science and Technology Studies (STS), was further refined by the works of Michael Callon, John Law, Nick Couldry among others. The ANT proposes a conceptual framework and analytical tool to understand the technological innovation being assimilated into any given establishment with all its processual implications, the minutiae of the working practices and the ways facts are constructed. Latour and Woolgar studied the Salk Institute for Biological Studies in San Diego for two years and then demystified the "mysterious scientific world" by providing the detailed descriptions emerging from 'following the actors' (Hemmingway, 2008). Applying the ANT to present study, the scientific laboratory and the scientific facts are to be read as newsroom and news respectively.

Actor-network theory (ANT) rejects the positivist proposition of presupposed dichotomies between nature/society, micro/macro, subject/object, good /bad, human/animal, and human/machine proposed by the classical sociology led by Emile Durkheim and Auguste Comte. Instead, the ANT embraces the flat ontology where these binaries are not accepted and where all actors are given equal level playing field (Dudhwala, n.d.). In an attempt to dedifferentiate, the ANT delegates equal power to both human and nonhuman actors. It is through their association with other actors that they can exert their power. An actor:

...is any element that bends space around itself, makes other elements dependent upon itself and translates their will into a language of its own (Callon \& Latour, 1981, p. 286).

Actors have been termed as actants with a view to neutralising the term. Actants are made of three things- humans and animal, technologies and gods (Hemmingway, 2008, p. 23). Journalists, human actors, working in the newsroom and the infrastructure and technologies, the non-human actors, being applied in the newsroom would be dubbed as actants. Like human actors, even the nonhuman actors such as central server or hub play a significant role in the news production process (Hemmingway, 2005). Network indicates the interconnection, intersection and interaction among several nodes. Actors, resources, notes, guidelines, statements, infrastructure, etc. constitute as each node. These nodes may be situated anywhere in the network. The network extends the newsroom to outer nodes and the nodes situated at periphery bring the reality into the newsroom. This should not be equated with internal and 
external reality. There is no fixed start or end point in the network. The network suggests that:

...resources are concentrated in a few places - the knots and the nodes - which are connected with one another - the kinks and the mesh - these connections transform the scattered resources into a net that may seem to extend everywhere (Latour, 1987, p.180).

The network of the ANT is very identical to the concept of rhizome proposed by Deleuze and Guattari (1987) in their book A Thousand Plateaus. Deleuze and Guattari opposed the generation and organisation of knowledge in arborescent (tree like) manner and proposed instead that it is assembled in planar and rhizomatic manner. Rhizome rejects the dualities of a fix beginning and resolution. It is always in the middle, in between and at intermezzo level.

Translation is the process by which actor(s) interact with other actors and an actor' space gets expanded through the enrolment of more actors into its alliance. It is through the translation that actors exert their power and change other actors' behaviour. It is an on-going process which involves creation of multiples actor-networks. Callon (1980,) defines translation as "creating convergence and homologies by relating things that were previously different". Translation is also characterised by the resistance put forward by other actors with a view to opposing an actor's will and power (Hemmingway, 2008, p. 23). When an actant succeeds in making an alliance by enrolling often discrete actors and when its concomitant practices become stabilised and unquestioned, actant attains the black box status. The black box status of any actant shows that it has faced the trials of strength successfully in any network, it is momentarily locked and impermeable to disagreement (Latour, 1987).

Intermediaries and mediators are other key components of ANT (Fioravanti and Vehlo, as cited by Spyridou et al., 2013). Intermediaries exert less power while mediators "transform, translate, distort and modify" other actors (Dudhwala, n.d.). The sociologists of social prefer an assemblage where there are more intermediaries and less mediators whereas the sociologists of association (ANT) do not have any preference for specific social segregation and where there are more mediators all jostling with and against each other (Latour, 2005). Immutable mobiles facilitate the translation process but remain unchanged themselves. Statistics, questionnaires, charts, guidelines and inscription devices can be termed as immutable mobiles (Hemmingway, 2008). 
These immutable mobiles are transformed from one actor to another and they stabilise the network.

\section{Methodology}

To understand the phenomena of social media, mobile phones and other convergent technologies being integrated into the newsroom culture, qualitative research design has been adopted. In-depth interviews with twelve journalists from Hindustan Times and Hindustan Dainik, Lucknow and Dainik Jagran, Allahabad were conducted in the month of March, 2015. Hindustan Times, the English newspaper and Hindustan Dainik, the Hindi newspaper run under the same publication group. Both the newspapers are being operated on the different floors of a single building in Lucknow.

The profile of journalists includes copy editor, senior copy editor, chief copy editor, chief sub-editor, general manager, assistant manager, photojournalist, special correspondent and sub editor-cum-reporter. The interviews were audio-recorded with prior consent of the subjects (journalists) and later on transcribed for analysis which was carried out during July-August, 2015. Coding was done following the three stages of thematic analysis (Kings \& Horrocks, 2010). Qualitative data analysis software, NVivo, has also been used to analyse the transcripts. Journalists' name has been anonymised. The selection of the newspaper and the journalists for interview was based on convenience.

\section{Analysis}

\section{Technological agency of mobile phone and smart phones}

Mobile phones and smart phones have become instrumental for the journalistic works (Pavlik, 2000). Mobile phone has changed the way how journalists collect inputs and talk to their sources (Pavlik, 2004). It is becoming as essential as computer. Be it asking for news updates, clarifying any issue or simply talking to fellow journalists, the mobile phone has made the conversation process much simpler. Senior copy editor at Hindustan Times tells:

...It is quite simpler to connect with reporters via mobile phone in comparison to the office phone where we need to type the num- 
bers. You just can talk to them over mobile phone or you can just send them text message.

Mobile phones have become quintessential and have reconfigured production of news stories starkly. With the help of these convergent technologies (mobile and smart phones), news events can be covered economically in terms of time and material resources. Given the accessibility brought in by the mobile phone, stories can be prepared even without going outside the newsroom. The mobility of mobile phones has caused a reduction in the running around and the physical movements but the importance of actually going to the field cannot be denied. As chief sub-editor, Dainik Jagran, Allahabad illuminates on this aspect:

Yes of course, physical movement has decreased. There are two things regarding the bodily movement. It is true that we needn't to go to the field sometimes and we can prepare the news out of the material available on WhatsApp or other platforms but if you go to the field you will necessarily get something new or interesting dimension to the story. It is useful for those who want to stay in the newsroom itself but those who go the field, they will get benefited.

As far as collection and verification of news stories are concerned, the mobile phone and smart phones have the agency to alter the journalistic practices. They have translated the relationship of journalists with their sources and fellow journalists and the way journalists interact with them. This nonhuman actant appears to have acquired important position in the journalistic network. However, the semi black box status of the mobile and smart phones is subject to challenge and change. Chief sub-editor at Dainik Jagran, Allahabad indicates towards the amenability of semi-black box status of mobile phones:

There is great deal of decrease in the physical movement but no doubt we have to go the field also sometimes. We had one incident where there was no event and we received even the press notes also... Had we not verified it, we would have published the press note. Whenever there is any big event, you have to go to the field. As far as small events or soft news stories are concerned, you can manage even without going to the field. 
The strategies (ill-conceived) of human actors, the magnitude of big news events and the quality concerns put a resistance to the punctualisation/blackboxing of mobile phones.

\section{The CMS as obligatory point of passage}

The content management software (CMS) or the central server helps the news institution organise and manage all the resources, assignments and activities. Through the central server, newsrooms also become connected to other newsrooms for the purpose of collaboration. Both the newspapers - Hindustan Times and Hindustan Dainik - use NewsWrap as the CMS. Microsoft content management software is being us ed at Dainik Jagran. Sub-editorcum-reporter at the Hindustan Dainik tells that NewsWrap is very useful. According to him,

NewsWrap is used for as content management software. Through NewsWrap, we can send the news items to other desks and we receive various news items on NewsWrap itself coming from news agencies...While preparing any news story, I keep on checking NewsWrap to see whether there are any new stories or new development in any previous story.

Chief copy editor, Hindustan Dainik, also holds similar views regarding the CMS:

NewsWrap is such a technology through which we can share our stories with each other. We can send our story to anyone in the newsroom or at other places. We can see who is checking our Quark pages. This technology is being adopted by many newspapers.

The CMS is considered as the life line of any newspaper as all the activities surrounding the journalism are organised and managed through it. Almost all the journalists, people at the managerial level and technical assistants are supposed to interact with the CMS routinely. All the stories are fed into the software and stories from the news agencies and other sources are routed to newsroom via the CMS. Assistant Manager (IT) Dainik Jagran, Allahabad tells about the crucial role of the CMS in following words: 
Our content management software is the life line of our newspaper. We are connected to all of our centres. We can share stories in a reciprocal way with our other centres. It is central database for all the activities in the newsroom. It helps journalist do their job in a proper way. If any story gets repeated, it recognizes that story and informs that the concerned story has been published with details of edition and location.

The CMS or the central server becomes the obligatory point of passage for almost the all the news stories, journalists, management and the technical team as well thus attaining the status of black box. The CMS and associated practices have been hailed as stabilised, normal and necessary. Journalists can be resistant to upcoming software for page designing or video and photo editing, but their resistance towards the CMS would be feeble. By the virtue of the very starting point and obligatory point of passage for everyone, the CMS turns into black box. The uncontested status of CMS indicates that it has successfully translated other actors' behaviour and enrolled other actors and/or constellation of actors into its alliance. The practices related to the CMS become so normalised that no one question it.

The CMS and enfolded actors (technical assistants) enjoy a more privileged position in the newsroom. The complexity of the functioning of the server, necessity and easiness of the tasks to be performed through the CMS and the expertise of technicians make the CMS stable. Further, the black box status or punctualisation of the CMS is intensified by the very acknowledgement of the fact that the functioning of server and system is contingent and it may fail also. In such case, the cognoscenti (technical assistants) would come for rescue. Assistant Manager (IT) Dainik Jagran, Allahabad elaborates on this aspect:

We have another second line in case of emergency. If our main server gets failed, we have our second server to help us. If any journalist faces any problem regarding technical things, we help them. We can't wait for tomorrow rather we have to do our job now. We find solution to the problem. Work is to be done instantly. In journalism, the most important thing is the time so we can't delay anything. 


\section{Real time conversation with multimedia content through WhatsApp}

WhatsApp has emerged as significant messaging app. Journalists can have real-time conversation with their fellow workers and friends. They can share multimedia content via WhatsApp. It is influential in doing the journalistic work. Whatever is happening around the world, journalists get updated with every single detail via WhatsApp. Furthermore, WhatsApp has changed the nature of interaction between journalists and their sources (Pavlik, 2004). First of all, journalists needn't to go the field to meet their sources personally rather they can talk over phone. Secondly, if necessary, source can send the entire data via WhatsApp. Additionally, reporting from the field is being heavily negotiated and shaped by WhatsApp. Reporters from the field can send the text, photo, audio, and video and if needed contacts as well. The story can be broken instantly with inputs from WhatsApp. Full-fledged story can be prepared later on. While talking about the role of WhatsApp, senior copy editor at Hindustan Dainik says in following words:

I use WhatsApp and I think that WhatsApp has changed journalism a lot. We get all the information regarding the office meeting, events taking place, the details about the field and beat of journalists and all other aspects of journalism.

Other messaging apps like Facebook Messenger and Google Hangout are being used by journalists but when compared to WhatsApp, these apps are not so frequent. General Manager, Dainik Jagran, Allahabad highlights the potentials of WhatsApp when it comes to reporting from the field as this:

With WhatsApp, our reporters can break the news from anywhere.

They need to just click the photo and send it though WhatsApp.

They are able to do real-time reporting with WhatsApp.

WhatsApp has also proved to be beneficial for photojournalists as well. Photojournalists can share their photos with their colleagues, if necessary, and at the same time they can send the photos to the newsroom instantly without going to the newsroom. Journalists accept that sometimes they are not able to get reach at the site of news event and in such case they have their own network of fellow journalists with whom they exchange the photos. Photojournalist, Dainik Jagran, Allahabad tells about the contribution to WhatsApp in his routine as follows: 
WhatsApp is more personal unless you distribute your number to a large of people... We have many groups on WhatsApp and we have added many other organizations to our group. So we usually get many stories via WhatsApp. I am here and if I shoot any photo, I update the photo through WhatsApp. I needn't to go to the office.

The functionalities and easiness of working with WhatsApp have of course elevated it to a point where it becomes obligatory for almost everyone. All the human actors in and around the newsroom, with few exceptions, are supposed to have WhatsApp account and utilise it for performing their tasks. Along with other black boxes, WhatsApp too has attained central stage. The indispensability of WhatsApp in the daily routine of journalists makes it a black box. As ANT posits that any black box isn't permanent and is subject to questioning. Though actants may accept the black box as the obligatory point but they don't always surrender- they can put resistance also. Chief sub-editor, Dainik Jagran, Allahabad do accepts the "black boxness" of WhatsApp but sometimes he expresses his resistance by the way deleting some WhatsApp messages thus negating the translation:

Since we are always available on WhatsApp, we are receiving a lot number of messages at every moment. I can't read these messages. It is very difficult to filter out messages. I have many unseen messages. Ultimately, I will have no option but delete all the messages. Sometimes it becomes very hectic and difficult to deal with but then you have survival issue.

Though it's difficult to deal with innumerable messages coming through WhatsApp, journalists are again left with no option but to see the messages due to the survival issues. WhatsApp has managed to enrol other actors in its network in such a way that jettisoning its use may render the journalists unfit. WhatsApp is reassuring its black box status.

\section{Social media as prime site for networking, sharing and getting news up- dates}

Social media has emerged as prominent medium to connect to the near and dear ones, colleagues, friends and readers irrespective of temporal and spatial 
restrictions. Social media sites, especially Facebook, prove to be powerful and expressive medium in that journalist can speak their mind. Whatever they are not able to write in the main journalistic narratives, they can express freely on social media. Facebook and Twitter have been evolving as essential medium for discussion and debate. Since, they can't keep an eye on all the news websites due to time constraints, Facebook and Twitter have evolved as key referral medium for them. If there is any major incident, they get updated via social media. Further, social media sites like Facebook and Twitter have proved to be valuable in terms of getting in touch with readers. Journalists get responses from their readers. Special correspondent at Hindustan Times opines about social media:

Generally with Facebook and Twitter, we are abreast of new information. On Twitter, you have many news feeds; so in that way you are abreast of new updates... Usually I get responses from readers on various aspects of stories. Some readers like the story and some don't like at all. It is kind of regular feature of our daily life.

Blogs, tweets and posts written by high profile celebrities most often constitute as ingredients for news. Moreover, other journalists accept that sometimes they get the story ideas from shares, debates and discussion happening on social media. Many journalists agree that they sometimes get the full news stories first hand via Facebook and Twitter. Chief sub-editor, Dainik Jagran, Allahabad narrates the importance of social media with respect to gauging popular sentiment and at the same time cautions against the issue of authenticity:

...If we are not on Facebook and Twitter, we can't guess as what is going in there and what is the popular sentiment. You see the Anna movement was brought to success because of social media. Social media gave a huge platform to this movement. We do get story ideas from social media and we make story out of that idea but we do not take full story from social media. Social media has the problem of authenticity. Anyone can write anything. Unless we verify those statements and posts, we can't write. 
Photojournalist, Dainik Jagran, Allahabad tells about one incident when he along with other journalists prepared a news story based on the inputs given on Facebook:

Facebook is quite helpful in many respects... I have one incident where we prepared one story based on the inputs given on social media. There is a locality called Shankargarh across the bank of Yamuna. That locality was facing the problem of water-scarcity. Someone posted on Facebook that there people were forced to take water from pond. We took up the issue and made a fullfledged story.

Social media sites and blogging and micro-blogging sites which used to be performing the intermediary roles once, have turned into the principal mediator when it comes to preparing and disseminating news stories and deciding the newsworthiness of any event. By guessing the popular sentiments on social media, which is now a mediator, journalists decide which stories to be covered and which aspects of the stories to be focussed on.

\section{Inscription devices of guidelines working as the immutable mobile}

Guidelines regarding the use of certain words, the word limit, the structure of the news, websites to be opened in the peak hour among others constitute as inscription devices into the newsroom. These devices facilitate the translation process in the network. Sometimes fliers can be seen, indicating the choice of words, word limit and the instructions to be adhered to by the journalists regarding the structure of news, stuck on the notice boards and near the desks where journalist will be working. These fliers can be termed as inscription devices. Photojournalist, Dainik Jagran, Allahabad explains about the guidelines issued by his organisation that govern his behaviour related to photography:

Yes, we have some guidelines regarding the camera and Photoshop. We are instructed as how take photos in day time, at night or at twilight time and what should be correct combination of aperture and shutter speed. 
The irrefutability of the importance of inscription devices and stabilised position in the network turn it into immutable mobile. These devices change the actions of other actors but remain unchanged and fixed.

\section{Discussion}

Mobile phones and smart phones have taken a crucial position in the newsroom. The significance of smart phones is very similar to that of computer. This super device (Dekerf et al., as cited by Appelgren, 2004) is profoundly affecting and shaping the journalistic work. With the advent of WhatsApp, multimedia content can flow across platforms. Smart phones with apps and internet facility can be dubbed as the device convergence (Flynn, as cited by Appelgren, 2004) as the features peculiar to certain platforms all are converged in a single device. Furthermore, the content management software (CMS), namely NewsWrap and Microsoft CMS, seems to be working as the principal mediator in the daily routines of journalists. Social networking along with mobile phone is proving to be beneficial for journalists in terms of writing and sharing their views, getting response from readers and colleagues, being informed on various activities taking place on social media which has become important referral medium to news websites and getting stories ideas from the posts and debates among others. Furthermore, social media and mobile phones have changed significantly the relationship between journalists and their sources. Journalists from newspaper are no longer 'recalcitrant technophobes' (O'Sullivan and Heinonen, 2008) rather they are adapting to new journalistic practices and work culture ushered in by media convergence.

It is clear from the above analysis that various actants including journalists, managers, technicians, reporters, photojournalists, assistants, organizational set up, technologies and associated practices, content management system, page designing software, statements, guidelines and readers, inter alia, constitute a complex journalistic network (Latour, 1987, 2005; Law, 1999; Latour \& Woolgar, 1979; Callon, 1981; Callon \& Latour, 1981; Cottle \& Ashton, 1999; Hemmingway, 2008). Lots of explicit and implicit interactions and transactions take place among these actants which are situated at different nodes of the network. WhatsApp, Facebook, Twitter, the content management software or central server (NewsWrap) and page-making software namely QuarkXPress and Adobe InDesign have become prominent nonhu- 
man actors which are interacting with other actors continuously in a 'nomadic manner and rhizomatic shape' (Deleuze \& Guattari, 1987), establishing associations, alliances and connection and translating multiple actor-networks. WhatsApp has ushered in tremendous change in the form of reporting and breaking the news in print journalism. Likewise computer, mobile and smart phones appear to be playing the role of mediator in that influencing the journalistic work heavily. As few journalists accept that they get story ideas from Facebook, it indicates that social networking sites have become crucial mediators when it comes to striking story ideas in some cases (Facebook) and disseminating the news story (Facebook and Twitter).

The agency of content management software or central server (NewsWrap and Microsoft CMS) seems to be working as "black box" (Latour, 1987, 2005; Latour \& Woolgar, 1979; Callon, 1981; Callon \& Latour, 1981; Hemmingway, 2008) in that the CMS takes the central stage. All actants - both human and nonhuman - are supposed to touch the obligatory point of passage which is the CMS. All the news stories prepared and sent by journalists, news agencies and other sources are routed via the CMS. Though the black box status of the CMS shows that it is stabilised momentarily, it has faced the 'trials of strength' successfully and it is accepted by other actors unquestioningly. Constellation of other actors (acebook, Twitter, mobile phones and WhatsApp) engages in sustained negotiation with the black box and tries to challenge the black box status of the CMS in itself. These actors put forward resistance against the black box. The resistance is also a part and parcel of the translation process. The semi-black box status of mobile phone is challenged by the big events and the quality concerns. Sometimes the stress due to imploding messages through WhatsApp is translated into vociferous resistance leading the human actor to delete or ignore the messages. Social networking sites, blogging and micro-blogging sites, messaging apps and mobile phones extend the journalistic network from the encircled boundaries of newsroom to the fenceless multiple locations of the network (Latour, 1987, 2005). Furthermore, the network also gets extended to other locations via the NewsWrap when journalists share their stories, see other journalists' stories, get suggestions and keep on receiving updates from news agencies. Thus, the concentrated resources are distributed and transformed through connection and links among various nodes and knots (Latour, 1987). Thus, the journalistic network 
of news production indicates a planar, nomadic and rhizomatic structure of the news organisation (Deleuze \& Guattari, 1987).

It is obvious from the analysis that news technologies are at work in and around the newsroom. The attendant practices of these technologies indicate a great deal of translation or alteration of the journalistic network in terms of how journalists do their work and how the resources of the organisation and the knowledge produced are coordinated. Since this paper is focused on exploring only the translation of the journalistic network, further focused research is needed to enquire how these news technologies are themselves getting altered or translated.

To conclude, the exploration of news production network which is heterogeneous and full of complexities should not be concluded so easily because ANT doesn't believe in the rendering of knowledge in simple, transparent, singular and formulaic manner (Law, 1999). Predisposition to look for pinnacle and simplicity should be resisted.

\section{Note}

A part of this paper was presented at the National Seminar organised by the Dept. of Media Studies, Garden City College, Bengaluru.

\section{Acknowledgement}

The researchers are thankful to Mr. Ankit Kumar Singh, Mr. Dheeraj Kumar and Mr. Sandeep Dube for their kind help.

\section{References}

Appelgren, E. (2004). Convergence and divergence in media: Different perspectives. Proceedings of the $8^{\text {th }}$ ICCC International Conference on Electronic Publishing: 237-248.

Boczkowski, P. J. (2004). The process of adopting multimedia and interactivity in three online newsrooms. Journal of Communication, 54(2): 197213. doi: 10.1111/j.1460-2466.2004.tb02624.x.

Callon, M. (1981). Struggles and negotiations to define what is problematic and what is not: the sociology of translation. In K. D. Knorr-Cetina, R. 
Krohn \& R.D. Whitley (Eds.), The Social Process of Scientific Investigation. Dordecht, Holland: D. Reidel Publishing Co.

Callon, M. \& Latour, B. (1981). Unscrewing the Big Leviathan: how actors macrostructure reality and how sociologists help them to do so. In K.D. Knorr-Cetina \& A.V. Cicourel (Eds.), Advances in Social Theory and Methodology: Toward an integration of Micro- and Macro-Sociologies (pp. 277-303). Boston, Mass: Routledge and Kegan Paul.

Cottle, S. \& Ashton, M. (1999). From BBC newsroom to BBC newscentre: On changing technology and journalistic practices. Convergence, 5(3): 22-43. doi:10.1177/135485659900500304.

Cottle, S. (Ed.). (2003). Media Organisation and Production. London, Thousand Oaks, Calif and New Delhi: Sage Publications.

Deleuze, G. \& Guattari, F. (1987). A Thousand Plateaus: Capitalism and Schizophrenia. Athlone, London.

Dubberly, H. (2011). Convergence $2.0=$ service + social + physical. $A C M$ Interactions, 19.

Dudhwala, F. (n.d.). What is actor-network theory: What are its strengths and limitations as a form of sociological theory?. Retrieved from https://oxfo rd.academia.edu/FarzanaDudhwala

Hemmingway, E. (2005). PDP, the news production network and the transformation of news. Convergence, 11(3): 8-27. doi: 10.1177/135485650501 100302.

Hemmingway, E. (2008). Into the newsroom: Exploring the digital production of regional television news. London and New York: Routledge.

Jenkins, H. (2001). Convergence? I diverge. Technology Review.

Jenkins, H. (2004). The Cultural Logic of Media Convergence. International Journal of Cultural Studies, 7(1): 33-43. doi: 10.1177/13678779040406 03.

Jenkins, H. (2006). Convergence culture: Where old and new media collide. New York and London: New York University Press. Retrieved from http://en.bookfi.org/

King, N. \& Horrocks, C. (2010). Interviews in qualitative research. Los Angeles, London, New Delhi, Singapore, Washington DC: Sage. 
Latour, B. (2005). Reassembling the Social: An Introduction to Actor-Network Theory. Oxford: Oxford University Press. Retrieved from http://en. bookfi.org/

Latour, B. (1987). Science in Action. Cambridge, Mass: Harvard University Press.

Latour, B. \& Woolgar, S. (1979). Laboratory life - The social construction of scientific facts. Beverley Hills, Calif. and London: Sage

Law, J. (1999). After ANT: Complexity, naming and topology. In J. Law \& J. Hassard (Eds.), Actor Network Theory and After (pp. 1-14). Oxford: Blackwell.

Micó, J. L.; Masip, P. \& Domingo, D. (2013). To wish two impossible things*: Convergence as process of diffusion of innovations in an actor-network. International Communication Gazette: 75(1): 118-137. doi:10.1177/174 8048512461765 .

Negroponte, N. (1995). Being digital. Retrieved from http://en.bookfi.org/

O'Sullivan, J. \& Heinonen, A. (2008). Old values, new media. Journalism Practice, 2(3): 357-371. doi: 10.1080/17512780802281081.

Pavlik, J. (2000). The impact of technology on journalism. Journalism Studies, 1(2): 229-237. doi: 10.1080/14616700050028226.

Pavlik, J. V. (2004). A Sea-change in journalism: Convergence, journalists, their audiences and sources. Convergence, 10(4): 21-29. doi:10.1177/13 5485650401000404.

Robinson, S. (2011). Convergence crises: News work and news spaces in the digitally transforming newsroom. Journal of Communication, 61(6): 1122-1141. doi: 10.1111/j.1460-2466.2011.01603.x.

Rogers, E. (1995). Diffusion of innovation. New York: Free Press.

Spyridou, L-P.; Matsiola, M.; Veglis, A.; Kalliris, G. \& Dimoulas (2013). Journalism in a state of flux: Journalists as agents of technology innovation and emerging news practices. International Communication Gazette, 75(1): 76-98. doi: 10.1177/1748048512461763. 